\title{
Comparative Histological study of Normal human placentae with Hypertensive placentae in Western part of Tamilnadu state (Kongunadu region)
}

\section{Vijaianand $\mathrm{M}^{* 1}$, Geeta Anasuya D ${ }^{2}$, Sheela Grace Jeevamani ${ }^{3}$, Sutha $\mathrm{S}^{4}$.}

${ }^{{ }_{1} 1}$ Associate Professor, Department of Anatomy, $\mathrm{KMCH}$ Institute of Health Sciences and Research, Coimbatore, Tamilnadu, India.

${ }^{2}$ Assistant Professor, Department of Anatomy, KMCH Institute of Health Sciences and Research, Coimbatore, Tamilnadu, India.

${ }^{3}$ Professor and Head, Department of Anatomy, KMCH Institute of Health Sciences and Research, Coimbatore, Tamilnadu, India.

${ }^{4}$ Assistant Professor, Department of Anatomy, KMCH Institute of Health Sciences and Research, Coimbatore, Tamilnadu, India.

\section{ABSTRACT}

Background: Placenta forms an intimate bonding between the mother and the foetus. Apart from gaseous exchange, transport of nutrients from mother to the foetus, any disease or disorder affecting the mother also reflects the foetus. Hypertension during antenatal period produces maternal vasospasm and vascular damage due to luminal constriction of uterine spiral arterioles causing histological changes in the placenta and ultimately leads to foetal hypoxia and death.

Aim of the study: To compare the histological features between the normal and hypertensive placenta.

Materials and Methods: 30 normal and 30 hypertensive placentae were collected, processed in the Department of Anatomy, Karpagam Faculty of Medical Sciences and Research, Coimbatore, Tamilnadu, and visualised under light microscope and their histological features are noted.

Results: Various histological features obtained are Syncytial knots, Fibrinoid necrosis, Calcification of Placenta, Placental infarction, Stromal fibrosis, Hypovascularity of Villous, Intervillous fibrin deposition and Basement membrane thickening.

Conclusion: In our study, the histological features are more prominent and their areas in microscopic field is noted more in hypertensive placentae than normal placentae. Histtological features are mainly due to maternal vasospasm and vascular endothelial injury.The statistical analysis calculated for the histological features was found to be significant.

KEY WORDS: Placenta, Hypertension, Histology, Syncytial knots, Calcification.

Corresponding Author: Dr. Vijaianand M, Associate Professor, Department of Anatomy, KMCH Institute of Health Sciences and Research, Coimbatore, Tamilnadu, India.

E-Mail: dr.vijaitarun7474@gmail.com

\begin{tabular}{|c|c|c|c|}
\hline Access this Article online & \multicolumn{3}{|c|}{ Journal Information } \\
\hline \multirow[t]{3}{*}{ Quick Response code } & \multicolumn{3}{|c|}{$\begin{array}{l}\text { International Journal of Anatomy and Research } \\
\text { ISSN (E) 2321-4287 | ISSN (P) 2321-8967 } \\
\text { https://www.ijmhr.org/ijar.htm } \\
\text { DOI-Prefix: https://dx.doi.org/10.16965/ijar } \quad \text { (cc) Ev-NE-8f }\end{array}$} \\
\hline & \multicolumn{3}{|c|}{ Article Information } \\
\hline & $\begin{array}{l}\text { Received: } 14 \text { Feb } 2021 \\
\text { Peer Review: } 15 \text { Feb } 2021\end{array}$ & $\begin{array}{l}\text { Accepted: } 15 \text { Mar } \\
\text { Published (0): } 15\end{array}$ & $\begin{array}{l}21 \\
r 2021\end{array}$ \\
\hline DOI: 10.16965/ijar.2021.115 & Revised: None & Published (P): 05 & 2021 \\
\hline
\end{tabular}

\section{INTRODUCTION}

The term 'Placenta' was first coined in the year 1559. It is a vital organ that represents the cooperation of two distinct individuals which protects one and enables the genes of other. The bonding between the extra embryonic 
tissue of the embryo and endometrial tissue of the mother forms a symbiosis between two separate organisms without rejection, thereby suggesting the immunological acceptance of the foetal graft by the mother [1]. As it maintains pregnancy and promotes the growth of the foetus through its metabolic, secretory and excretory functions, it has been described as mirror of the perinatal period. Maternal genetic predisposing factors such as specific patterns of variant in angiotensinogen gene and presence of quantitative trait loci on chromosomes $5 q, 10 q$ and $13 q$ is considered important in acquiring Hypertensive disorders during pregnancy [2,3]. Hypertension associated with proteinuria during antenatal period is called pre-eclampsia or Pregnancy Induced Hypertension(PIH), which accounts for about $10 \%$ of pregnancies throughout the world [4,5]. In Pregnancy Induced Hypertension, as pregnancy advances the diameter of lumen of uterine spiral arterioles is reduced to $1 / 3^{\text {rd }}$ as compared to normal pregnancy as a result of this the placental perfusion gets decreased and infarction occurs, the foetal stem arteries undergo constriction which ultimately leads to fetal hypoxia, retarded growth of the fetus and fetal death [6-8].

According to previous studies, in India the reduction in Maternal mortality rate which was 570 per one lakh population in 1990 has been reduced to 230 per one lakh population in 2008, but however it seems to be high when compared to developed countries. Considering the above facts the present study has been carried out to find the histological features in placentae of hypertensive mothers and comparing the same with the placentae of normotensive mothers.

\section{MATERIALS AND METHODS}

A total of 60 placentae obtained from Department of OBG, Karpagam Faculty of Medical Sciences and Research, Coimbatore, Tamilnadu, South India, was selected for this study, of which 30 collected from antenatal mothers suffering from Hypertensive disorders and 30 from normotensive mothers. The study has been carried out for a period of 1 year and 6 months. The blood pressure ranging from $140 / 90 \mathrm{~mm}$ of $\mathrm{Hg}$ to $190 / 120 \mathrm{~mm}$ of $\mathrm{Hg}$ among the hypertensive mothers was taken into consideration. Criteria for selection of Placenta are,

Inclusion criteria: Normotensive and hypertensive mothers with age groups between 21-35 years, Gestational hypertension

Exclusion criteria: Women suffering from other metabolic disorders such as Diabetes mellitus, Hypothyroidism, etc. Placental deformities like abruptio placenta.

Collected Placentae were thoroughly washed in running tap water, sectioned into small bits and subjected to the following steps,

- Fixation - with $10 \%$ formalin

- Dehydration - with alcohol in ascending concentrations viz.70\%,90\% and absolute alcohol

- Clearing - with Xylene, this makes the tissue transparent so as to raise the refractive index - Impregnation - with paraffin wax Tissue blocks made

- Sectioning - done with Rotary microtome, section thickness ranges from $3-5 \mathrm{~mm}$ thickness [9].

- Deparaffinization - with Xylene

- Staining and Counterstaining-with Haematoxylin and Eosin

- Mounting - with DPX and examined under light microscope

Various microscopic fields have been visualised to obtain different histological features. The study design was an observational study and the data collected was analysed statistically using t-test, $n=30$ formula with the help of SPSS software version 27.

\section{RESULTS}

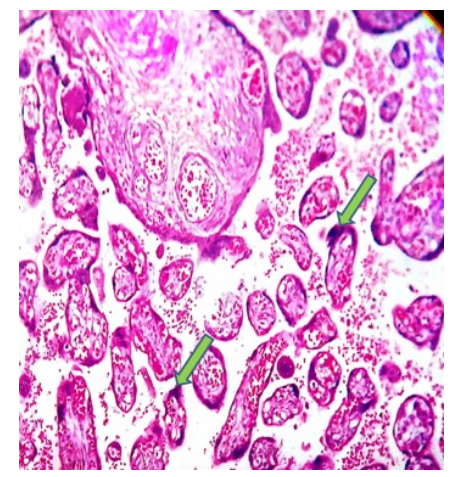

Fig. 1: Showing syncytial knots (Arrowed) 


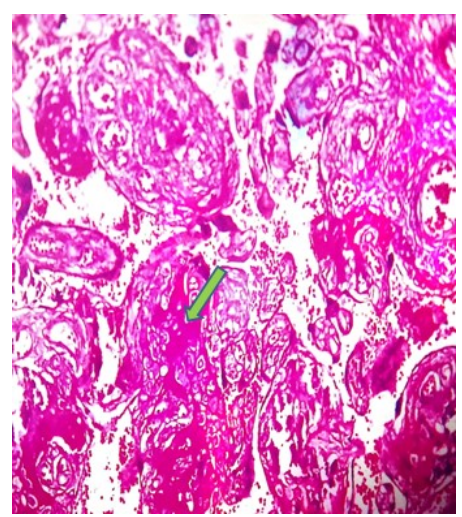

Fig. 2: Showing areas of Fibrinoid necrosis (Arrowed).

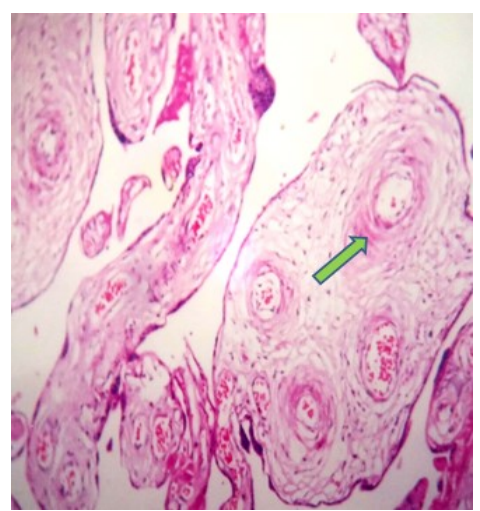

Fig. 5: Showing Stromal fibrosis (Arrowed)

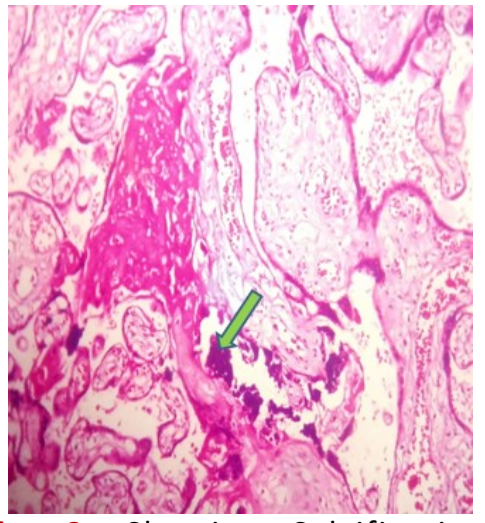

Fig. 3: Showing Calcification (Arrowed).

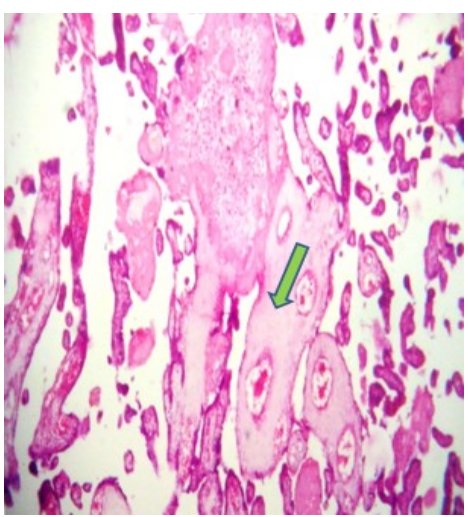

Fig. 6: Showing Villous hypovascularity (Arrowed)

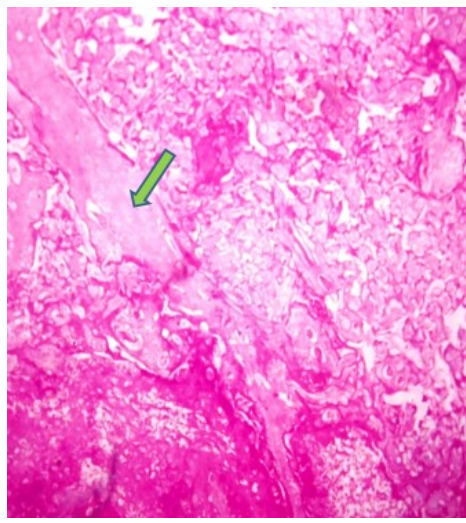

Fig. 4: Showing infarcted areas (Arrowed).

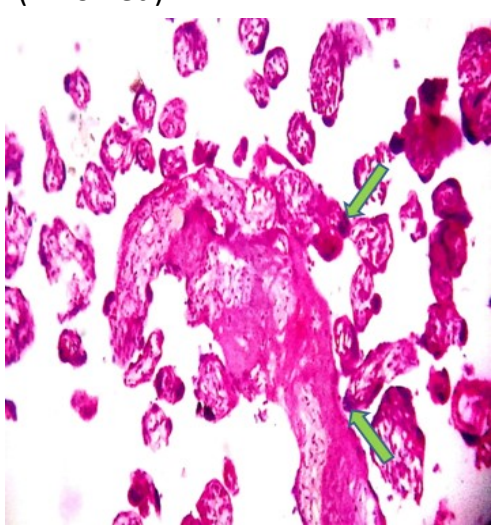

Fig. 7: Showing Intervillous fibrin deposition (Arrowed).

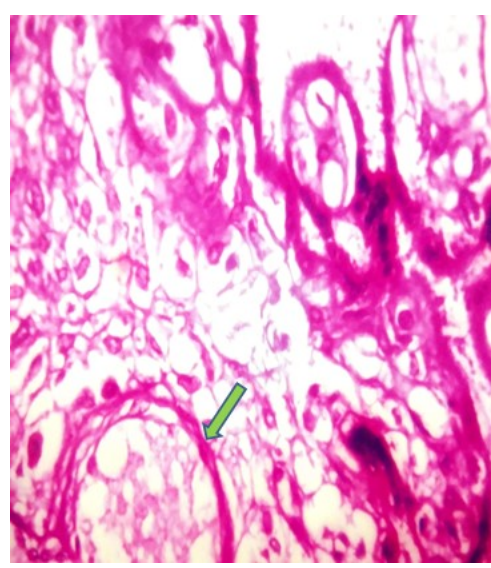

Fig. 8: Showing Thickened Basement membrane (Arrowed).

In the present study, a total of 60 Placentae [30-Normal;30-Hypertensive]were collected, processed and examined under a light microscope and the following Histological features are noted viz.Syncytial knots, Fibrinoid necrosis, Placental Calcification, Placental Infarction, Villous Hypovascularity, Intervillous fibrin deposition and thickened Basement membrane.From the above table it is evident that the Histological features has an increase in percentage in Hypertensive placenta as compared with Normal placenta.

Table 1: Histological features obtained through light microscopy.

\begin{tabular}{|llcccc}
\hline S.NO. & \multicolumn{1}{|c}{ Histological features } & $\begin{array}{c}\text { Present in } \\
\text { Normal } \\
\text { Placenta }\end{array}$ & $\begin{array}{c}\text { Present in } \\
\text { Hypertensive } \\
\text { Placenta }\end{array}$ & $\begin{array}{c}\text { Percentage in } \\
\text { Normal } \\
\text { Placenta }\end{array}$ & $\begin{array}{c}\text { Percentage in } \\
\text { Hypertensive } \\
\text { Placenta }\end{array}$ \\
\hline $\mathbf{1}$ & Syncytial knots & 9 of 30 & 19 of 30 & $30 \%$ & $63.30 \%$ \\
\hline $\mathbf{2}$ & Fibrinoid necrosis & 7 of 30 & 15 of 30 & $23.30 \%$ & $50 \%$ \\
\hline $\mathbf{3}$ & Placental Calcification & 6 of 30 & 17 of 30 & $20 \%$ & $56.60 \%$ \\
\hline $\mathbf{4}$ & Placental infarction & 4 of 30 & 14 of 30 & $13.30 \%$ & $46.60 \%$ \\
\hline $\mathbf{5}$ & Stromal fibrosis & 3 of 30 & 12 of 30 & $10 \%$ & $30 \%$ \\
\hline $\mathbf{6}$ & Villous hypovascularity & 3 of 30 & 13 of 30 & $10 \%$ & $43.30 \%$ \\
\hline $\mathbf{7}$ & Intervillous fibrin deposition & 6 of 30 & 11 of 30 & $20 \%$ & $36.60 \%$ \\
\hline $\mathbf{8}$ & Basement membrane thickening & 2 out of 30 & 12 out of 30 & $6.60 \%$ & $40 \%$ \\
\hline
\end{tabular}


Table 2: Group Statistics for Histological features seen under light microscope in low Power Field.

\begin{tabular}{|c|c|c|c|c|c|}
\hline S.No. & Histological features & Group & $\mathbf{N}$ & Mean & $\begin{array}{l}\text { Standard } \\
\text { Deviation }\end{array}$ \\
\hline \multirow{2}{*}{1} & \multirow{2}{*}{ Syncytial knots } & Hypertensive & 30 & 26.47 & 1.978 \\
\hline & & Normal & 30 & 8.93 & 1.596 \\
\hline \multirow{2}{*}{2} & \multirow{2}{*}{ Fibrinoid necrosis } & Hypertensive & 30 & 11.1 & 1.788 \\
\hline & & Normal & 30 & 3.33 & 0.994 \\
\hline \multirow{2}{*}{3} & \multirow{2}{*}{ Placental Calcification } & Hypertensive & 30 & 11.6 & 1.812 \\
\hline & & Normal & 30 & 3.43 & 1.104 \\
\hline \multirow{2}{*}{4} & \multirow{2}{*}{ Placental Infarction } & Hypertensive & 30 & 15.7 & 2.231 \\
\hline & & Normal & 30 & 1.33 & 0.844 \\
\hline \multirow{2}{*}{5} & \multirow{2}{*}{ Stromal fibrosis } & Hypertensive & 30 & 11.13 & 1.613 \\
\hline & & Normal & 30 & 2.8 & 0.805 \\
\hline \multirow{2}{*}{6} & \multirow{2}{*}{ Villous hypovascularity } & Hypertensive & 30 & 14.1 & 2.987 \\
\hline & & Normal & 30 & 1.1 & 0.845 \\
\hline \multirow{2}{*}{7} & \multirow{2}{*}{ Intervillous fibrin deposition } & Hypertensive & 30 & 13.93 & 2.212 \\
\hline & & Normal & 30 & 4.27 & 1.552 \\
\hline
\end{tabular}

Table 3: Independent Samples Test / Unpaired t-test.

\begin{tabular}{|c|c|c|c|c|c|c|c|c|}
\hline \multicolumn{2}{|c|}{ Histological Features } & \multicolumn{3}{|c|}{$\begin{array}{l}\text { Levene's Test for Equality of } \\
\text { Variances }\end{array}$} & \multicolumn{2}{|c|}{$\begin{array}{l}\text { t-test for Equality of } \\
\text { Means }\end{array}$} & \multicolumn{2}{|c|}{$\begin{array}{l}95 \% \text { Confidence } \\
\text { Interval of the } \\
\text { Difference }\end{array}$} \\
\hline & & Sig. & $\mathbf{t}$ & df & $\begin{array}{c}\text { Sig. } \\
\text { (2-tailed) }\end{array}$ & $\begin{array}{c}\text { Mean } \\
\text { Difference }\end{array}$ & Lower & Upper \\
\hline \multirow{2}{*}{ Syncytial Knots } & EVA & 0.184 & 37.785 & 58 & 0 & 17.533 & 16.604 & 18.462 \\
\hline & EVNA & & 37.785 & 55.519 & 0 & 17.533 & 16.604 & 18.463 \\
\hline \multirow{2}{*}{ Fibrinoid necrosis } & EVA & 0.001 & 20.794 & 58 & 0 & 7.767 & 7.019 & 8.514 \\
\hline & EVNA & & 20.794 & 45.37 & 0 & 7.767 & 7.015 & 8.519 \\
\hline \multirow{2}{*}{ Placental Calcification } & EVA & 0.014 & 21.081 & 58 & 0 & 8.167 & 7.391 & 8.942 \\
\hline & EVNA & & 21.081 & 47.934 & 0 & 8.167 & 7.388 & 8.946 \\
\hline \multirow{2}{*}{ Placental Infarction } & EVA & 0 & 32.993 & 58 & 0 & 14.367 & 13.495 & 15.238 \\
\hline & EVNA & & 32.993 & 37.14 & 0 & 14.367 & 13.484 & 15.249 \\
\hline \multirow{2}{*}{ Stromal fibrosis } & EVA & 0.008 & 25.316 & 58 & 0 & 8.333 & 7.674 & 8.992 \\
\hline & EVNA & & 25.316 & 42.604 & 0 & 8.333 & 7.669 & 8.992 \\
\hline \multirow{2}{*}{ Villous Hypovascularity } & EVA & 0 & 22.94 & 58 & 0 & 13 & 11.866 & 14.134 \\
\hline & EVNA & & 22.94 & 33.611 & 0 & 13 & 11.848 & 14.152 \\
\hline \multirow{2}{*}{$\begin{array}{l}\text { Intervillous Fibrin } \\
\text { Deposition }\end{array}$} & EVA & 0.023 & 19.595 & 58 & 0 & 9.667 & 8.679 & 10.654 \\
\hline & EVNA & & 19.595 & 51.988 & 0 & 9.667 & 8.677 & 10.657 \\
\hline
\end{tabular}

EVA- Equal Variances Assumed ; EVNA- Equal Variances Not Assumed

Table 2 revealed the mean number of areas of Syncytial knots seen under the light microscope in low power field is 26.47 in Hypertensive placenta and 8.93 in Normal placenta.Similarly for Fibrinoid necrosis is 11.10 in Hypertensive and 3.33 in Normal placenta, Placental calcified areas is 11.60 in Hypertensive and 3.43 in Normal placenta,Placental infarcted areas is $\mathbf{1 5 . 7 0}$ in Hypertensive and 1.33 in Normal placenta,Villous hypovascularity is 14.10 in Hypertensive and 1.10 in Normal placenta and Intervillous fibrin deposited areas are 13.93 and 4.27 for Hypertensive and Normal placenta respectively.Standard deviation and Standard error mean for all the Histological features were obtained
Table 3 Shows the statistical analysis done by Independent samples test. The two tailed $p$-value cal calculated for all the above Histological features was less than .0001 which indicates that it is statistically significant.

\section{DISCUSSION}

Hypertension developing during pregnancy not only produces histological changes in the placenta but also affects the fetal outcome. Once the fetus got delivered and the placenta when fully expelled there occurs ceasation in disease process. On the other hand it has been found that maternal blood pressure reduces fast following an immediate postpartum curettage than in places where it has not been 
done. Pregnancy Induced Hypertension (PIH) affecting the placental tissue has been seen in conditions such as hydatidiform moles even in the absence of fetus. Hypertension during pregnancy leads to more number of still births, almost 1.4 times more as compared with normotensive mothers [10]. An association between low birth weight babies and PIH has also been reported, which is 5 times more in $\mathrm{PIH}$ as compared with normotensive mothers[11].

Placenta exposed to hypoxia leads to loss of parenchymal cells that in turn appears as syncytial knots. Decrease in fetal villous perfusion is associated with increase in syncytial knots[12]. Decrease in intervillous blood flow leading to increase in syncytial knots formation is called Tenny-Parker changes which was stated by Tenny and Parker in 1940, this influence the maternal factors in Preeclampsia which might be the cause for the above concept[13]. Syncytial knots formation also increase with increasing gestational age. In the present study, syncytial knots were seen in $63.3 \%$ and $30 \%$ in hypertensive and normotensive placentae respectively. It almost coincides with the study made by Siva Sree Ranga et al which was $63.3 \%$ for hypertensive and $23.3 \%$ for normotensive placentae[14]. Similar studies done by Kantilal $M$ et al also closely coincides with our study where syncytial knots were seen in $69 \%$ in hypertensive and $38 \%$ in normotensive placenta[15]. The mean number of areas of syncytial knot formation seen under low power field in our study was 26.47 and 8.93 for hypertensive and normotensive placentae and it almost near to the study made by Pratishtha potdar which was $28.57 \pm 9.56$ for hypertensive placenta and $9.16 \pm 4.08$ for normotensive placentae[16], and similarly $23.15 \pm 4.84$ for hypertensive and $9.75 \pm 3.18$ for normotensive placentae in a study made by Prathiba A et al[17].

Fibrinoid necrosis affecting the placental villi with higher incidence is seen in $\mathrm{PIH}$ and the underlying pathology is due to increased changes seen in coagulation leading to damage of the endothelium. Initially it appears as a small drop of homogenous material which progressively increases leading to the replacement of villus with fibrin either from maternal or fetal blood $[18,19]$. In our study, we found fibrinoid necrosis in $50 \%$ of hypertensive placentae and $23.3 \%$ in normotensive placentae. In a study made by Narasimha $A$ et al fibrinoid necrosis was seen in $37 \%$ and $29.72 \%$ of hypertensive and normotensive placentae which was in close relation to our study [20]. The mean number of areas of fibrinoid necrosis seen under low power field in our study was 11.10 and 3.33 for hypertensive and normotensive placentae and it almost coincides with the study made by Prathiba A which was $7.05 \pm 2.87$ and 3.04 \pm 1.24 for hypertensive and normotensive placentae [17].

Calcification of placenta is considered as a degenerative change which may result by reduced vascularity to placenta particularly in conditions like PIH or may also occur due to aging of placenta [21]. In our study the percentage of placenta showing calcification was $56.6 \%$ and $20 \%$ for hypertensive and normotensive respectively, which closely coincides with the study made by Siva Sree Ranga MK et al and was $56.7 \%$ for hypertensive and $23.3 \%$ for normotensive placentae[14]. Kantilal observation regarding calcification was $53.8 \%$ and $35.8 \%$ for hypertensive and normotensive placentae[15]. The mean number of calcified areas seen under low power field in our study was 11.60 and 3.43 for hypertensive and normotensive placentae which was in near association with the study made by Pratishtha potdar of $11.71 \pm 5.57$ and $4.96 \pm 2.84$ for hypertensive and normotensive placentae[16].

Occlusion of maternal uteroplacental vessels due to thrombosis results in Placental infarction is more frequently seen in toxemia[22]. Placental infarction of less than $5 \%$ is common and if it exceeds beyond that it is considered abnormal. In the present study, we found placental infarction in $46.6 \%$ of hypertensive and $13.3 \%$ of normal placentae which nearby coincides with the study made by Kantilal M who recorded Placental infarction of $42.4 \%$ and $12.6 \%$ in hypertensive and normotensives[15]. The mean number of infarcted areas seen under low power field in our study was $\mathbf{1 5 . 7 0}$ 
and 1.33 for hypertensive and normotensive placenta. Reduction in fetal perfusion to placenta may result in the formation of stromal fibrosis[12]. Obliterative endarteritis leading to decreased uteroplacental blood accounts for an higher incidence of stromal fibrosis. In the present study, stromal fibrosis recorded in hypertensive is more in hypertensive as compared to normal, coinciding with the studies reported by many authors. Vascularity to villous is reduced in PIH which in turn is also associated with degenerative changes like calcification of placenta[23].In our study, villous hypovascularity was seen in $43.3 \%$ of hypertensive placentae and $10 \%$ of normal placentae, whereas Susheela Rana made a study and reported villous hypovascularity in $30 \%$ of hypertensive and $2 \%$ of normal placentae[24].The mean number of areas with decreased vascularity of villous seen under low power field in our study was 14.10 and 1.10 for hypertensive and normal placentae. $36.6 \%$ of hypertensive and $20 \%$ of normal placentae showed deposition of fibrin in between the villous from our study and the mean number of areas with intervillous fibrin deposition was 13.93 and 4.27 for hypertensive and normotensive placentae. Thickening of basement membrane occurs due to increased cytotrophoblastic proliferation are highly seen in $\mathrm{PIH}$. In the present study, trophoblastic basement membrane thickening was seen more in hypertensive placentae as compared with normal placentae and Prathiba $A$ et al also reported a higher incidence in hypertensive placentae[17].

\section{CONCLUSION}

About $10 \%$ of the world's pregnancy are complicated by hypertension which irreversibly affects both mother and fetus thereby causing a big threat to the society in the form of maternal and fetal morbidity and mortality. The uterine spiral arteries that were normal before conception undergoes some modifications following decidual implantation of blastocyst and during placentation. This results in deficient trophoblastic invasion by the spiral arteries leading to maternal vasospasm and vascular endothelial injury and has been considered as a major cause for hypertension to occur and produce histological changes in the placenta. Though the proportion (number of placenta) may vary from study to study done by many authors, It is evident from our study and other studies, that the histological features are more pronounced and highly enhanced in hypertensive placentae as compared with normal. The statistical analysis was done by Independent samples test. The two tailed $p$-value calculated for all the above mentioned histological features in this study was less than .0001 , which indicates that it is significant statistically. With advancement in the field of medicine and new inventions such as three dimensional ultrasonography and computer-aided virtual organ analysis, the changes occuring in the placenta and fetal growth can be identified accurately and the maternal and fetal abnormalities can be highly declined.

\section{Conflicts of Interests: None}

\section{REFERENCES}

[1]. Aparna Narasimha, DS Vasudeva. Spectrum of changes in placenta in toxemia of pregnancy 2011;54(1):15-20.

[2]. Van Dijk M, Mulders J, Poutsma A. Maternal segregation of the Dutch preeclampsia locus at $10 q 22$ with a new member of the winged helix gene family. Nat Genet 2005;37:514-519.

[3]. Ohnson MP, Fitzpatrick E, Dyer TD. Identification of two novel quantitative trait loci for pre-eclampsia susceptibility on chromosomes $5 q$ and $13 q$ using a variance components-based linkage approach. Mol Hum Reprod 2007;13:61-67.

[4]. Arshad A, Pasha W, Khattak TA, Kiyani RB. Impact of pregnancy induced hypertension on birth weight of newborn at term.2011;15(2):113-5.

[5]. Robertson WB, Brosens I, Dixon HG. The pathological response of the vessels of the placental bed to hypertensive pregnancy. J Pathol Bacteriol.1967 Apr;93(2):581-92.

[6]. Browne JM, Veall N. The maternal placental blood flow in normotensive and hypertensive women. BJOG: Int J Obstet Gynaecol.1953 Apr;60(2):1417.

[7]. Stock MK, Anderson DF, Phernetton TM, McLaughlin MK, Rankin JH. Vascular response of the maternal placental vasculature. J Dev Physiol 1980;2:239246.

[8]. Thomson AM, Billewickz, Hytten FE. Placenta in relation to birth weight. J Obstet Gynaecol $\mathrm{Br} \mathrm{CW}$ 1969;76: 865-872.

[9]. Carolyn M Salfia,Edwina J Popek.Placenta in Anderson's Pathology Vol.II.10 ${ }^{\text {th }}$ Ed. Ivan Domjanov, Mosby, Missourie. 1996;2310-2353. 
[10].Allen VM, Joseph KS, Murphy KE, Magee LA, Ohlsson $A$. The effect of hypertensive disorders in pregnancy on small for gestational age and stillbirth: a population based study. BMC Pregnancy Childbirth.2004 Dec;4(1):17.

[11]. Keche HA, Keche AS. Morphometric differentiation between placenta in $\mathrm{PIH}$ and normal pregnancy. Int J Med Sci Public Health.2015 Feb 1;4:250-5.

[12]. Genset D.R. (1992): Estimating the time of death of still born fetuses. A study of 71 still born, Brit. J. obst.gynae., 1992;80;585-592.

[13]. Tenney B, Parker F. The placenta in toxemia of pregnancy. Am J Obstet Gynaecol 1940;39:1000-5.

[14]. Siva Sree Ranga MK, Adaline Thangam TF, Mallika MC, Indira MV. Morphological and histological variations of human placenta in hypertensive disorders of pregnancy. Int J Anat Res. 2017;5(1):3591-98.

[15].Kantilal M, Parmar, Gopal V. Shah, Ravi R. Alamchandani. Histological evaluation of placenta in hypertensive pregnancies. Int J Res Med Sci 2019;7:40-5.

[16]. Pratishtha Potdar, Deepak Naik, P G Khanwalkar, B $K$ Sharma.A comparative histological study of human placentae obtained from mothers with $\mathrm{PIH}$ and mothers with normal blood pressure. International Journal of Recent Trends in Science and Technology. February 2016;18(1):185-188.

[17].Prathiba A, Einstien D, Subramanian V, Mahendranath $P$, Murugesan S. Comparative Study of Placental Morphometry and Histomorphology in Normal and Pre-eclamptic Pregnancies. Int J Sci Stud 2016;4(9):96-99.
[18]. McKay DG, Hertig AT, Adams EC, Richardson MV. Histochemical observations on the human placenta. Obstetr Gynaecol. 1958 Jul 1;12(1):1-36.

[19]. Wigglesworth JS. Morphological variations in the insufficient placenta. BJOG.1964 Dec 1;71(6):87184.

[20]. Narasimha A, Vasudeva DS. Spetrum of changes in placenta in toxemia of pregnancy. Indian Journal of Pathology and Microobiology. 2011 Jan $1 ; 54(1): 15-20$.

[21]. Fox H. General pathology of the placenta. In: Fox $H$, editor. Haines and Taylor Obstetrical and Gynaecological Pathology. 4th ed. Edinburgh: Churchill Livingstone: 1995:1480-2.

[22]. Kher AV, Zawar MP. Study of placental pathology in toxemia of pregnancy and its fetal implications. Indian J Pathol Microbiol. 1981;24:245-51.

[23]. Rohini Motwani, Yogesh Sontakke, Meena Goyal. Effects of pregnancy induced hypertension on human placenta. J Evolution of Medical and Dental Sciences 2013;2(33):6275-6282.

[24]. Susheela Rana, Yogesh Diwan, Randhir S Chauhan, Deepa Diwan, Ankur Gupta. Comparative Stusy of Histology of Placenta in Normotensive and Hypertensive Cases. Journal of Medical Science and Research. Vol 05.Issue 03;Page 18635-18640;March 2017.

How to cite this article: Vijaianand M, Geeta Anasuya D, Sheela Grace Jeevamani, Sutha S. Comparative Histological study of Normal human placentae with Hypertensive placentae in Western part of Tamilnadu state (Kongunadu region). Int J Anat Res 2021;9(2.1):79487954. DOI: $10.16965 /$ ijar.2021.115 